\title{
Hard X-ray photoelectron spectroscopy study of thermal effect on chemical state of sulfur in rubber compound
}

\author{
K. Ozawa ${ }^{*}$, T. Kakubo², N. Amino², E. Ikenaga ${ }^{3,4}$ \\ ${ }^{1}$ Department of Chemistry, Tokyo Institute of Technology, Meguro, 152-8551 Tokyo, Japan \\ ${ }^{2}$ The Yokohama Rubber Co., Ltd., Hiratsuka, 254-8601 Kanagawa, Japan \\ ${ }^{3}$ Institute of Materials and Systems for Sustainability (IMaSS), Nagoya University, Nagoya, 464-8603 Aichi, Japan \\ ${ }^{4}$ Japan Synchrotron Radiation Research Institute (JASRI), SPring-8, Sayo, 679-5198 Hyogo, Japan
}

Received 6 August 2018; accepted in revised form 1 October 2018

\begin{abstract}
Hard X-ray photoelectron spectroscopy (HAXPES) has been utilized to study chemical state and kinetics of sulfur species in a rubber compound by examining thermally induced changes of S 1s core-level spectra. Two peaks at 2470 and $2472 \mathrm{eV}$ together with the $2479 \mathrm{eV}$ peak from $\mathrm{SO}_{4}^{2-}$ are resolved in the $\mathrm{S} 1 \mathrm{~s}$ spectrum. As the rubber compound is heated at 374,412 , and $440 \mathrm{~K}$, the former two peaks show different thermal behaviors; the peak at $2472 \mathrm{eV}$ is swiftly decreased in its intensity with heating time because of thermal desorption of the sulfur species, whereas the intensity of the $2470 \mathrm{eV}$ peak shows a slight increase especially in the surface region of the rubber compound. On the basis of these thermal behaviors, the peaks at 2470 and $2472 \mathrm{eV}$ are, respectively, associated with $\mathrm{S}$ atoms bonded directly to the $\mathrm{C}$ atoms and those bonded only to other S atoms. An Arrhenius plot analysis of the $2470 \mathrm{eV}$ peak intensity variation reveals that the S-C bond formation and scission reactions compete with each other with a slightly smaller activation energy in the bond formation than in the bond scission.
\end{abstract}

Keywords: rubber, vulcanization, reversion, hard X-ray photoelectron spectroscopy

\section{Introduction}

Vulcanization is a chemical process that converts plastic materials into elastic materials and is a very important process especially in the rubber industry. When vulcanization of natural rubber is carried out with sulfur, a soft rubber compound is converted to a harder and more durable compound because of the formation of crosslinks. Sulfur added to the rubber compound plays an essential role in crosslinking; polymeric sulfur bridges individual rubber molecular chains so that the degree of freedom of molecular motion is restricted [1]. The elasticity of vulcanized rubber is determined by the density of the crosslinks, that can be controlled not only by the amount of added sulfur [2] but also by vulcanization temperature and time $[3,4]$. For the rubber compound used in automotive tires, for example, the amount of sulfur added to the uncured rubber compound ranges, depending on the tire part, from 1.5-2 parts per hundred rubber [phr] for a tread and side walls to $5-8 \mathrm{phr}$ for a steel belt. Vulcanization is carried out typically at $150-180^{\circ} \mathrm{C}$ for $10-40 \mathrm{~min}$ (the higher the temperature is, the shorter the required heating time is).

Sulfur is also essential to realize strong adhesion between rubber and metal. Rubber-metal composites are used in many applications such as vibration absorbers, aseismic base isolation systems, automotive tires, and so on [5]. In some of these applications, the metal parts are brass-plated to realize firm and stable rubber-metal adhesion, since it has been recognized that rubber-brass bonding is quite strong. Strong rubberbrass adhesion arises from the formation of a copper

${ }^{*}$ Corresponding author, e-mail: ozawa.k.ab@m.titech.ac.jp (C) BME-PT 
sulfide layer, which serves as an adhesive agent at the interface between rubber and brass [6].

On the other hand, during long-term usages of the rubber products, excess sulfur in the rubber compound is known to lead to an undesired increase in the crosslink density to make the rubber compound stiffer (increasing an elastic modulus) [7]. Excess sulfur also affects the rubber-metal adhesion properties [7]. The dual role of sulfur, both positive and negative, therefore, makes the control of sulfur very important to realize the rubber compound that is suitable for a target rubber product.

Kinetics of sulfur vulcanization of natural rubber have been extensively studied [3, 4, 8, 9] even after the comprehensive studies by Coran in 1960s [10-12]. Chough and Chang estimated the apparent activation energies of sulfur vulcanization to be approximately $1 \mathrm{eV}$ [3]. Ding and Leonov further examined degradation of the crosslinks, called reversion, and estimated the activation energy of $1.57 \mathrm{eV}$ [8]. To deduce these thermodynamic parameters, changes of the vulcanization degree, i.e., the crosslink density, have been tracked using techniques such as a differential scanning calorimetry, rheometry, and a vulcameter torque change method, and the experimental data have been analyzed under proper kinetic models. This allows to reconstruct the behavior of sulfur in the rubber compound. However, very few studies have focused on the relation between chemistry of sulfur and its kinetic behavior. In the present study, therefore, we applied hard X-ray photoelectron spectroscopy (HAXPES) to examine sulfur chemical state in the rubber compound and its change during a heat treatment to obtain an atomistic view of sulfur behavior.

X-ray photoelectron spectroscopy (XPS) is a powerful tool to make a chemical state analysis of composite elements of solid materials because high-sensitivity and high-energy-precision measurements are possible. Owing to very short inelastic mean free path of emitted photoelectrons in the solid, XPS is a surface-sensitive technique. On the other hand, there has been an increasing demand for a bulk investigation by XPS, and, therefore, XPS utilizing a hard X-ray, i.e., HAXPES, has been developed and becomes nowadays a popular tool that can determine a chemical state and an electronic structure in the bulk [13]. In our HAXPES study for the rubber compound, we used the hard X-ray with a photon energy $(h v)$ of $7.94 \mathrm{keV}$ and mainly analyzed S 1 s photoelectrons with the kinetic energy of around $5.47 \mathrm{keV}$. This allowed us to verify the chemical states of sulfur in the rubber compound as deep as $34 \mathrm{~nm}$ from the surface. In the present paper, influences of in situ thermal processing on the sulfur migration in the rubber compound, desorption from the compound surface, and the $\mathrm{C}-\mathrm{S}$ bond formation and scission are examined and discussed on the basis of the HAXPES data.

\section{Experimental}

HAXPES measurements were carried out at a beamline BL47XU of SPring-8 [14]. The spectra were acquired by a hemispherical electron energy analyzer (R4000, VG Scienta, Sweden) with a wide-acceptance-angle electrostatic objective lens, whose acceptance angle was $\pm 30^{\circ}$. The angle between the lens axis and the incident light was $90^{\circ}$, and the sample surface was aligned so that a light incidence angle was $40^{\circ}$ (measured from the surface normal direction). Thus, the photoelectrons emitted with a takeoff-angle (TOA) between 10 and $70^{\circ}$, which corresponds to the detection angle $\theta_{\mathrm{d}}$ between 80 and $20^{\circ}$ relative to the surface normal direction, were collected in an angular mode and analyzed. The photoelectrons with large TOAs carry bulk information, whereas those with smaller TOAs originate from the sample surface as well as from the near-surface region. The HAXPES spectra were acquired with an energy resolution of $0.3 \mathrm{eV}$, which was determined from a shape of a Fermi cutoff in the spectra of a gold plate. The position of the cut-off was used as a reference of the binding energy of the HAXPES spectra presented below.

Rubber samples subjected to the measurements were prepared as follows. An uncured, or unheated, rubber compound was sliced into a thin flake with a size of about $1 \mathrm{~mm} \times 0.7 \mathrm{~mm} \times{ }^{t} 0.4 \mu \mathrm{m}$ using a cryo-ultramicrotome (UMT UC7, Leica Microsystems, Germany). The rubber flake was placed on a mirror-polished brass plate $\left(5 \mathrm{~mm} \times 5 \mathrm{~mm} \times{ }^{\mathrm{t}} 0.5 \mathrm{~mm}\right)$, which was then mounted on a $\mathrm{Cu}$ sample holder. Figure 1a shows optical images of a typical rubber flake on the brass plate fixed on the holder.

Formulation of the rubber compound used in the present study is listed in Table 1. This formulation, which is characterized by a high sulfur additive, is the same as that used for a steel belt of an automotive tire. In the steel belt, brass-plated steel cords are embedded and firmly bonded to the surrounding rubber compound. To realize strong adhesion between steel 

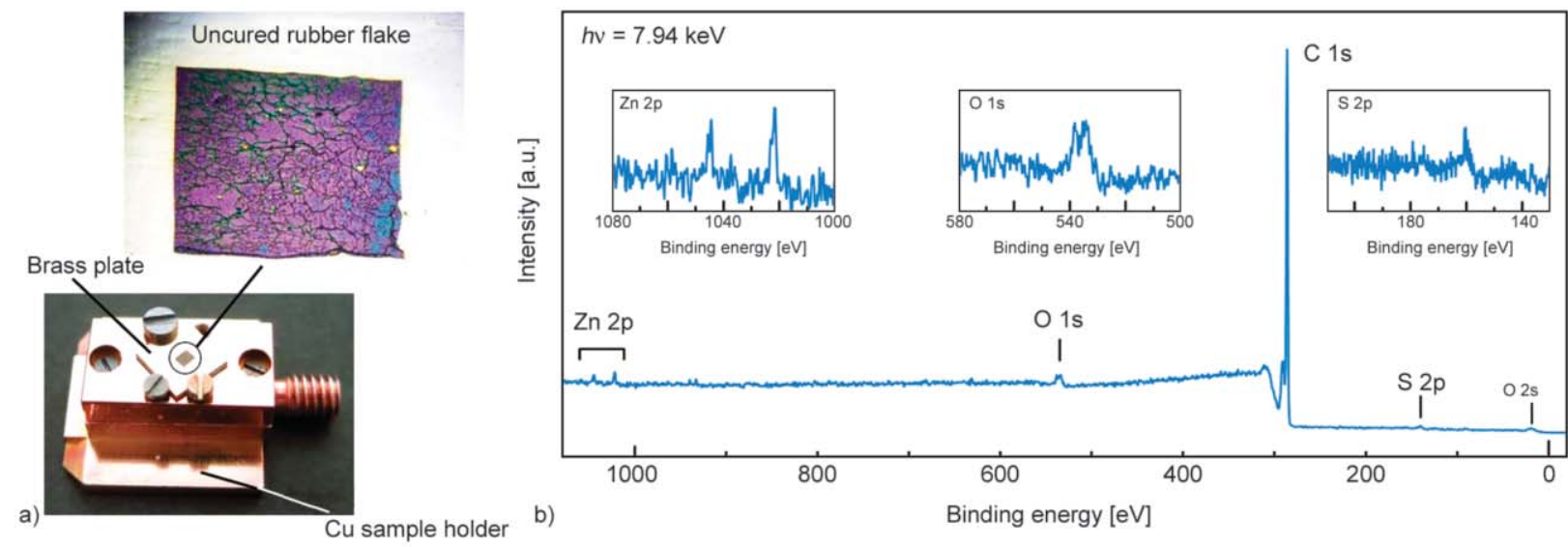

Figure 1. (a) Optical images of an uncured rubber flake and a sample holder. Although the rubber flake was gray-black in color, the captured image was violet because a polarizing filter was placed in front of the camera lens. (b) A widerange HAXPES spectrum of the uncured rubber compound measured with $h v=7.94 \mathrm{keV}$. The spectrum was measured in a transmission mode.

Table 1. Formulation of the rubber compound [phr; parts per hundred rubber].

\begin{tabular}{|l|c|}
\hline Natural rubber & 100 \\
\hline Carbon black (HAF-LS) & 60 \\
\hline Zinc oxide & 10 \\
\hline Sulfur (octasulfur, $\left.\mathrm{S}_{8}\right)$ & 8 \\
\hline Cobalt stearate & 2 \\
\hline Antioxidant $^{\mathrm{a}}$ & 1 \\
\hline Curing accelerator $^{\mathrm{b}}$ & 0.5 \\
\hline
\end{tabular}

${ }^{a} N$-phenyl- $N$ '-(1,3-dimethylbuthyl)-p-phenylenediamine (6PPD)

${ }^{\mathrm{b}} N, N$-dicyclohexyl-2-benzothiazole sulfonamide (DCBS)

and rubber, the compound with the high sulfur concentration (thus, the accelerator/sulfur ratio is lower than the conventional rubber [15]) is usually used. Since the present study was one of a series of our studies that verify steel-rubber adhesion properties [16-18], which were found to be largely influenced by the amount of sulfur accumulated at the steel/rubber interface, we examined in the present study kinetic behaviors of sulfur in the steel belt rubber. It is noted that rubber compounds used in other parts of the automotive tires have accelerator/sulfur ratios between 0.5 and 0.7 with 1 phr of an accelerator and $1.5-2$ phr of sulfur.

The rubber sample was transferred to an ultrahigh vacuum (UHV) chamber (the base pressure of $2 \cdot 10^{-7} \mathrm{~Pa}$ ) for the HAXPES measurements via a load-lock chamber. The $\mathrm{Cu}$ sample holders (Figure 1a) were inserted into a holder acceptor which was heated to desired temperatures of $T=374,421$, and $440 \mathrm{~K}$ by a ceramic heater. The rubber sample was, thus, heated under the UHV by conduction heating. Since the sample temperature was not directly measured, the HAXPES spectra were measured around $1 \mathrm{~h}$ after the sample holder was inserted in the acceptor so as to ensure that the sample temperature reached equilibrium. Three different rubber flakes were used, each of which were heated at 374,421 , and $440 \mathrm{~K}$. The employed heating temperatures are lower than a vulcanization temperature for the tire rubber (460$480 \mathrm{~K}$ ) in order to easily track thermal changes. The pressure during heating does not exceed $2 \cdot 10^{-6} \mathrm{~Pa}$.

\section{Results and discussion}

Figure $1 \mathrm{~b}$ shows a typical example of a wide-range HAXPES spectrum of the uncured rubber compound. A C $1 \mathrm{~s}$ peak at $\sim 285 \mathrm{eV}$ dominates the spectrum, while $\mathrm{O} 2 \mathrm{~s}, \mathrm{~S} 2 \mathrm{p}, \mathrm{O} 1 \mathrm{~s}$, and $\mathrm{Zn} 2 \mathrm{p}$ peaks are also observed but with very low intensities. Sulfur and $\mathrm{ZnO}$ additives are mainly responsible for the $\mathrm{O}$, $\mathrm{S}$, and $\mathrm{Zn}$ peaks. Absence of $\mathrm{Cu}$ peaks means that the rubber flake is thick enough to not to reach the rubber/brass interface by HAXPES.

As the rubber compound is heated at $440 \mathrm{~K}$, the lineshape of the $\mathrm{C} 1 \mathrm{~s}$ spectrum is hardly affected even after a prolonged heating of $18.5 \mathrm{~h}$ (Figure $2 \mathrm{a}$ ), although the peak position moves slightly to the lowerbinding-energy side (the peak shift was caused by a slight change of the photon energy with the time). The robust peak shape implies that the chemical state of $\mathrm{C}$ in the rubber compound, namely, $\mathrm{C}$ of the rubber molecules and the carbon black additive, is not affected by the heat treatment. On the other hand, the lineshape of the S 1s spectrum (Figure 2b) undergoes a substantial change; the peak at $\sim 2472 \mathrm{eV}$ is initially more intense than that at $\sim 2470 \mathrm{eV}$, while the intensity ratio is reversed at longer times by a significant intensity decrease of the $2472 \mathrm{eV}$ peak. The 

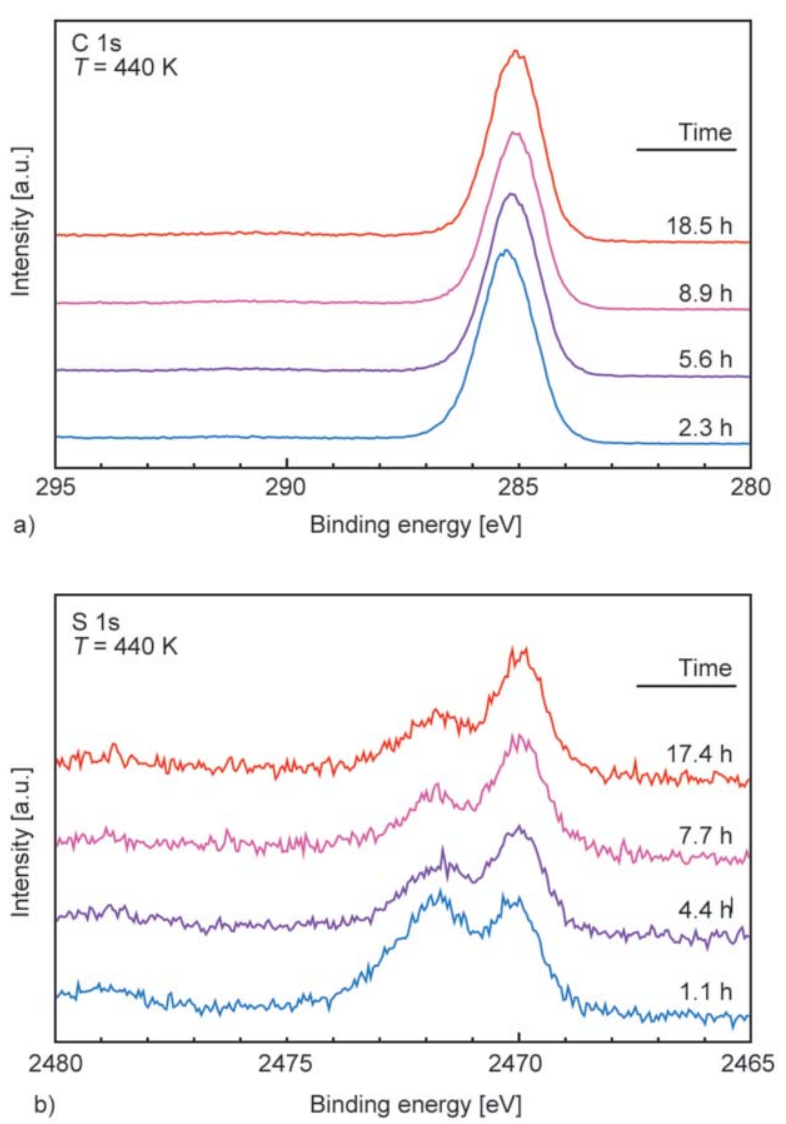

Figure 2. Angle-integrated HAXPES spectra in the $\mathrm{C}$ 1s region (a) and the $\mathrm{S} 1 \mathrm{~s}$ region (b) acquired while the rubber component was heated at $T=440 \mathrm{~K}$. The acquisition times for the $\mathrm{C} 1 \mathrm{~s}$ and $\mathrm{S} 1 \mathrm{~s}$ spectra were 13 and $22 \mathrm{~min}$, respectively. The heating times indicated are median values.

two-peak structure of the $\mathrm{S}$ 1s spectrum has also been observed for the vulcanized rubber [16]. In our preceding study [16], they were temporarily associated with $\mathrm{S}$ atoms directly bonded to the $\mathrm{C}$ atoms (the lower-binding-energy component) and $\mathrm{S}$ atoms in polymeric sulfur including $\mathrm{S}_{8}$ (the higher-binding-energy component). This peak assignment is plausible because, as we show below, polymeric sulfur is easy to migrate in the rubber compound and to desorb from the compound surface upon heating, while the S-C chemical bond makes the $\mathrm{S}$ atoms difficult to diffuse in the compound at such a low temperature.

To gain more insight into the heating-time dependence of the S 1s peak intensity, the S 1s spectra are quantitatively analyzed, and a result is shown in Figure 3. Figure 3a shows a time evolution of the S 1s spectra of the rubber compound heated at $440 \mathrm{~K}$. Each spectrum is reproduced by four Gaussian functions; one for the peak at $2470 \mathrm{eV}$, which is associated with the $\mathrm{S}$ atoms bonded to $\mathrm{C}$ and is denoted as ' $\mathrm{S}-\mathrm{C}$ ', one for the peak at $2472 \mathrm{eV}$, which originates from polymeric sulfur and is denoted as ' $\mathrm{S}-\mathrm{S}$ ', one for the peak at $2479 \mathrm{eV}$, which is assigned to the $\mathrm{SO}_{4}^{2-}$ species. The fourth Gaussian function contributes to the $\mathrm{S}-\mathrm{S}$ component and makes the $\mathrm{S}-\mathrm{S}$ peak shape slightly asymmetric. Note that the $\mathrm{S}-\mathrm{S}$ species include both the free polysulfur and the polysulfide crosslinks. The S-S peak intensity decreases with time along with the $\mathrm{SO}_{4}^{2-}$ peak, whereas the $\mathrm{S}-\mathrm{C}$ peak intensity is hardly affected or rather increases with time. This intensity variation is depicted in Figure $3 \mathrm{~b}$. The same $\mathrm{S} 1 \mathrm{~s}$ spectral measurements and analyses were carried out for the rubber compounds heated at 412 and $374 \mathrm{~K}$, and the resultant intensity variations are shown in Figures $3 \mathrm{c}$ and $3 \mathrm{~d}$, respectively. The trend of the intensity change for each component is the same as that shown in Figure $3 b$.

The magnitude of the intensity decrease for the $\mathrm{S}-\mathrm{S}$ and $\mathrm{SO}_{4}^{2-}$ peaks as well as the total intensity is enhanced with raising the heating temperature. Transformation of the polysulfide crosslinks to more stable mono- and disulfide crosslinks, the process known as reversion $[4,15]$, should be promoted at higher temperature. Fragmented polysulfide by the reversion as well as unreacted free polysulfur in the compound migrate to the surface, and a fraction of them is lost by isothermal desorption. The $\mathrm{SO}_{4}^{2-}$ species should also be removed in a similar manner. These thermal processes are responsible for the intensity decrease of the $\mathrm{S}-\mathrm{S}$ and $\mathrm{SO}_{4}^{2-}$ peaks. Thus, a first-order isothermal kinetics can be assumed to describe the intensity variation. Solid lines for the $\mathrm{S}-\mathrm{S}$ and $\mathrm{SO}_{4}^{2-}$ data in Figures $3 \mathrm{~b}-3 \mathrm{~d}$ are results of the least-squares fitting of the intensities $(I)$ to the biexponential function; $I=h_{\text {fast }} \cdot \exp \left(-t \tau_{\text {fast }}\right)+h_{\text {slow }} \cdot \exp \left(-t \tau_{\text {slow }}\right)$, where $h, \tau$, and $t$ are a fractional intensity, a decay time constant, and the heating time, respectively. The subscripts, 'fast' and 'slow', mean that there are two decreasing components with fast and slow decays. The slowly decaying component is found to have a time constant $\tau_{\text {slow }}$ of $400 \mathrm{~h}$ or longer irrespective of the species $\left(\mathrm{S}-\mathrm{S}\right.$ or $\mathrm{SO}_{4}^{2-}$ ) and the temperatures. On the other hand, the fast-decay time constants $\tau_{\text {fast }}$ are estimated to be $1.0-1.3 \mathrm{~h}$ for $\mathrm{S}-\mathrm{S}$ and $1.8-2.4 \mathrm{~h}$ for $\mathrm{SO}_{4}^{2-}$.

In contrast to the above mentioned two peaks, the $\mathrm{S}-\mathrm{C}$ peak shows an increasing trend with time. This indicates that a fraction of the $\mathrm{S}-\mathrm{S}$ species should be transformed to the $\mathrm{S}-\mathrm{C}$ species by forming $\mathrm{S}-\mathrm{C}$ bonds. Again, if the bond formation is assumed to be 

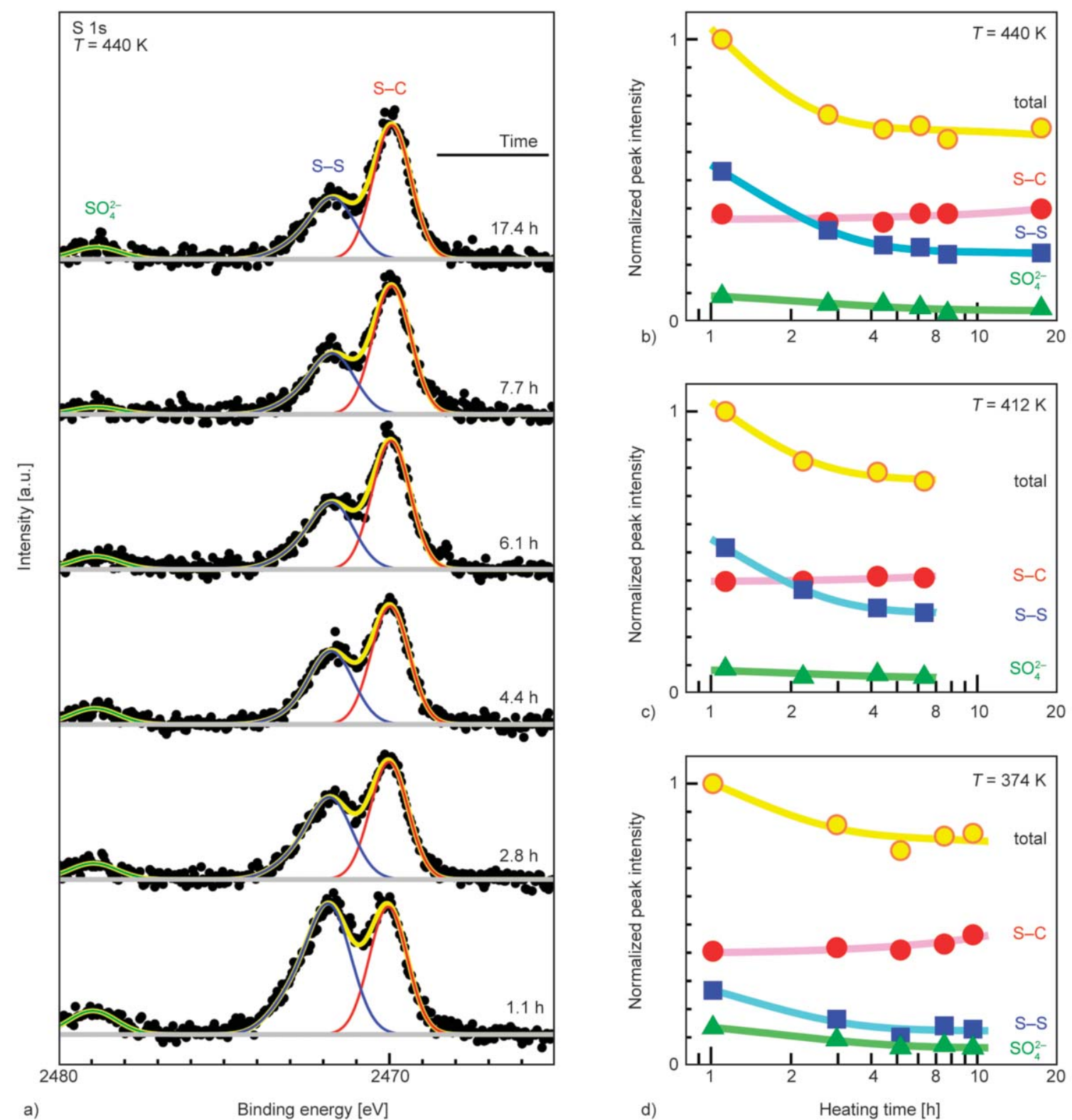

Figure 3. (a) Background subtracted S 1s spectra of the rubber compound heated at $440 \mathrm{~K}$ for different times from 1.1 to 17.4 h. The background was drawn by a Shirley-type curve. Each spectrum was fitted by Gaussian functions to reproduce three components $\left(\mathrm{S}-\mathrm{C}, \mathrm{S}-\mathrm{S}\right.$, and $\mathrm{SO}_{4}^{2-}$ ). (b-d) Heating time dependence of the spectral intensities of the three components and the total intensities for the heating temperatures of (b) $440 \mathrm{~K}$, (c) $412 \mathrm{~K}$, and (d) $374 \mathrm{~K}$. The intensity is normalized to the total $\mathrm{S} 1 \mathrm{~s}$ spectral intensity at $\sim 1 \mathrm{~h}$. A solid line in each panel is a result of curve fitting assuming an exponential decay of the peak intensities.

a first-order reaction (and this assumption is rationalized by the fact that the density of the $\mathrm{C}=\mathrm{C}$ group of the rubber molecules is much higher than that of sulfur), the S-C peak intensity should vary exponentially. Solid lines passing through the points tagged as $\mathrm{S}-\mathrm{C}$ in Figures $3 \mathrm{~b}-3 \mathrm{~d}$ are obtained by fitting the $\mathrm{S}-\mathrm{C}$ data to a single exponential function, $I=h \cdot \exp (-t \tau)$. Time constants are obtained as $\tau=170,130$, and $70 \mathrm{~h}$ for $T=440,412$, and $374 \mathrm{~K}$, respectively. An inverse correlation between $\tau$ and $T$, namely, a negative value of an apparent activation energy, indicates that the
$\mathrm{S}-\mathrm{C}$ bond scission, known as a reversion phenomenon, should also proceed. An Arrhenius plot of $\ln (1 / \tau)$ against $1 / T$ gives a straight line with a positive slope, from which the difference of the activation energies between the bond formation and cleavage is obtained as $0.2 \mathrm{eV}$. The fact that the $\mathrm{S}-\mathrm{C}$ peak intensity increases with time indicates that the activation energy of the bond formation is smaller than that of the bond scission. Chough and Chang estimated the activation energy of sulfur vulcanization of natural rubber, butadiene rubber, and styrene-butadiene rubber using 
a rheometer and differential scanning calorimetry [3] and found the activation energy of around $1 \mathrm{eV}$ irrespective of rubber (for natural rubber, it was $1.0 \pm 0.2 \mathrm{eV})$. By taking this value as the activation energy of the $\mathrm{S}-\mathrm{C}$ bond formation, the activation energy of the $\mathrm{S}-\mathrm{C}$ bond scission should be estimated as $1.2 \mathrm{eV}$. Although the value is slightly smaller than the apparent activation energy of the reversion process reported by Ding and Leonov $(1.57 \mathrm{eV})[8]$, the present and preceding studies all indicate that sulfur vulcanization proceeds faster than the reversion process.

To elucidate the thermal effect on the depth distribution of sulfur, angle-resolved HAXPES data were analyzed. Here, we focus on the $\mathrm{S}-\mathrm{S}$ and $\mathrm{S}-\mathrm{C}$ species. Figure $4 \mathrm{a}$ shows photoelectron intensity maps of the S 1s spectra of the rubber compound at $T=440 \mathrm{~K}$. Two bright bands at 2472 and $2470 \mathrm{eV}$ correspond to the $\mathrm{S}-\mathrm{S}$ and $\mathrm{S}-\mathrm{C}$ species, respectively. The intensity distribution as a function of the detection angle $\left(\theta_{\mathrm{d}}\right)$, which is characterized by a stronger intensity at larger $\theta_{\mathrm{d}}$ (smaller TOAs) is typical for the system that the composite element of interest is accumulated in the surface and near-surface regions [19]. Thus, the concentration of both $\mathrm{S}-\mathrm{S}$ and $\mathrm{S}-\mathrm{C}$ species are high in these regions at $t=1.1 \mathrm{~h}$. This is suggestive that migration and desorption of the sulfur species have already started in the first $1 \mathrm{~h}$ of heating. As has already been seen in Figure 3, Figure 4a indicates again that the $\mathrm{S}-\mathrm{S}$ intensity swiftly decreases with the heating time, while the $\mathrm{S}-\mathrm{C}$ intensity is persistent.

Figure $4 \mathrm{~b}$ shows the $\mathrm{S} 1 \mathrm{~s}$ spectra which are obtained by integrating the angle-resolved spectra in Figure $4 \mathrm{a}$. The spectra in the left panel are the integrated spectra between $\theta_{\mathrm{d}}=40$ and $80^{\circ}$, which represent the chemical state of the sulfur species distributed from the
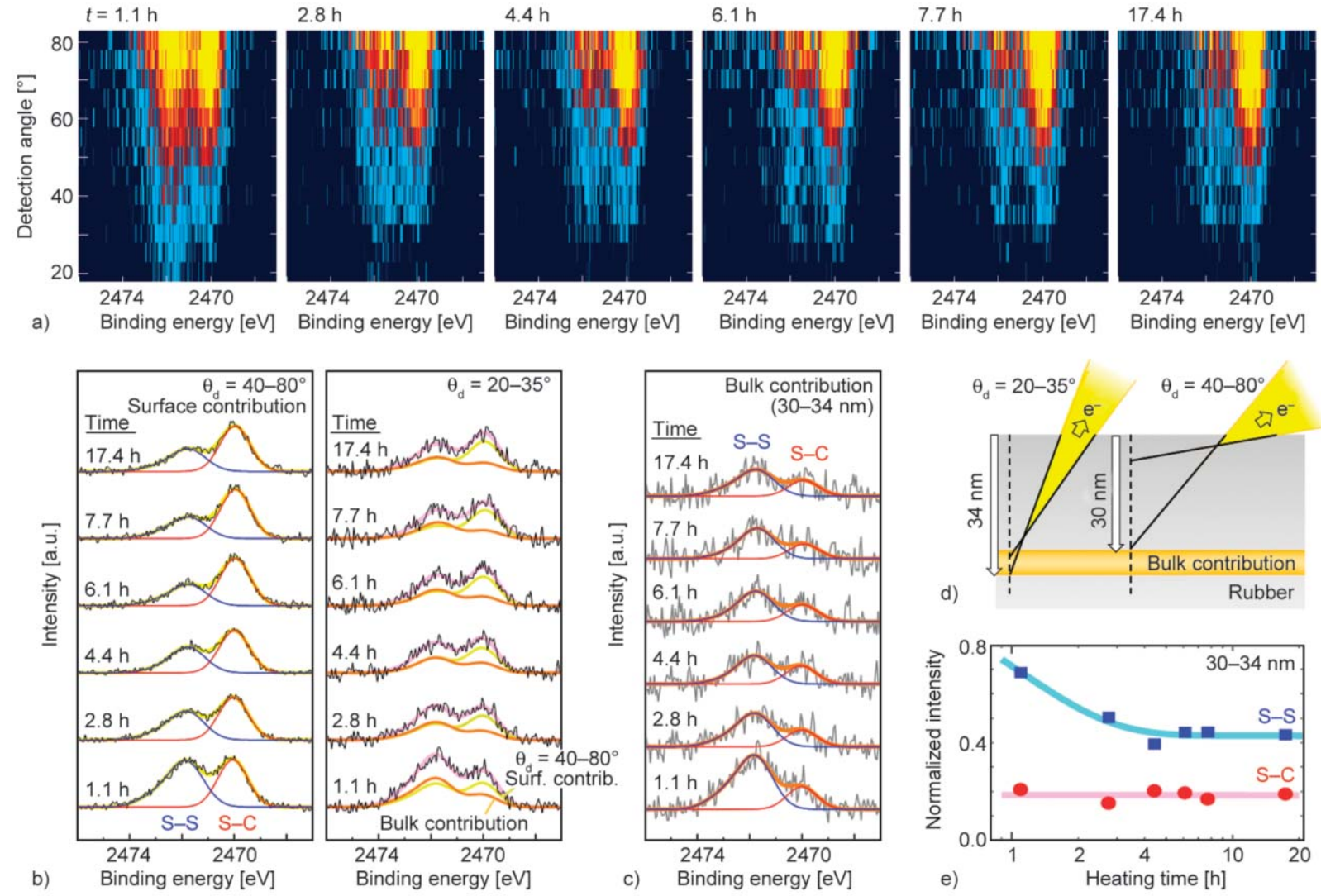

Figure 4. (a) Photoemission intensity plots of the angle-resolved S $1 \mathrm{~s}$ spectra of the rubber compound heated at $T=440 \mathrm{~K}$. The detection angle of $0^{\circ}$ corresponds to the direction normal to the surface. (b) Integrated S 1s spectra between the detection angles of 40 and $80^{\circ}$ (left) and those between 20 and $35^{\circ}$ (right). The former spectra are deconvoluted into the $\mathrm{S}-\mathrm{C}$ and $\mathrm{S}-\mathrm{S}$ components in the surface region (a surface contribution), while the latter spectra can be divided into the surface and bulk contributions. (c) Results of peak fitting of the bulk contribution of the S 1s spectra. (d) Schematic illustrations of the detection depths. The depths of 30 and $34 \mathrm{~nm}$ are information depths [20] and are derived from an inelastic mean free path of the $\mathrm{S} 1 \mathrm{~s}$ photoelectrons in the rubber compound (12.1 nm by a Seah's equation [21]), emission angles $\left(\theta_{\mathrm{d}}=20\right.$ and $\left.35^{\circ}\right)$, and a factor of 3. (e) Annealing time dependence of the $\mathrm{S}-\mathrm{S}$ and $\mathrm{S}-\mathrm{C}$ components that are distributed between 30 and $34 \mathrm{~nm}$. 
rubber surface to the depth of $30 \mathrm{~nm}$ (see Figure 4d). Each spectrum is composed of the contributions from the S-S $(2742 \mathrm{eV})$ and $\mathrm{S}-\mathrm{C}(2740 \mathrm{eV})$ species. Intensity variations of the $\mathrm{S}-\mathrm{S}$ and $\mathrm{S}-\mathrm{C}$ species over the heating time are very similar to that shown in Figure $3 \mathrm{~b}$; a swift decrease of the S-S intensity and a very slow increase in the $\mathrm{S}-\mathrm{C}$ intensity. This similarity is understood because the surface and nearsurface contributions dominate the integrated spectra shown in Figure 3a.

The spectra in the right panel of Figure $4 \mathrm{~b}$ are obtained by an integration of the angle-resolved spectra between $\theta_{d}=20$ and $35^{\circ}$. Since the spectra reflect the sulfur chemical state as deep as $34 \mathrm{~nm}$, the spectra can be decomposed into the surface contribution (between the surface and $30 \mathrm{~nm}$ ) and the bulk contribution (between 30 and $34 \mathrm{~nm}$ ), as shown by bold solid lines tagged as 'surface contribtion' and 'bulk contribution', respectively. The spectra in Figure $4 \mathrm{c}$ are bulk extracted spectra, each of which is obtained by subtracting the fitted curve of the integrated spectrum between 40 and $80^{\circ}$ (the left panel in Figure $4 \mathrm{~b}$ ) from the raw integrated spectrum between 20 and $35^{\circ}$ (the right panel in Figure 4b). The spectra shown in Figure $4 c$ are considered to represent the chemical states of bulk sulfur, because spectra having a similar lineshape to those shown in Figure 4c were obtained when the integrated spectra between 35 and $45^{\circ}$ were analyzed in the same way. As shown in Figure 4c, the bulk extracted spectra are further deconvoluted into the $\mathrm{S}-\mathrm{S}$ and $\mathrm{S}-\mathrm{C}$ components. In the bulk extracted spectra, the $\mathrm{S}-\mathrm{S}$ intensity largely reduces over the annealing time, while the $\mathrm{S}-\mathrm{C}$ intensity is hardly affected (Figure 4e). The S-S intensity decrease in the bulk indicates that the density of the polymeric sulfur is reduced in the bulk. The reduction time constant is 1.1 $\mathrm{h}$ in the first $5 \mathrm{~h}$, which is similar to that obtained for the S-S intensity variations in Figures $3 b-3 d(1.0$ $1.3 \mathrm{~h}$ ). This implies that the thermal diffusion of polymeric sulfur should be a rate determining step for the loss of sulfur by the diffusion-desorption process.

The concentration of the $\mathrm{S}-\mathrm{C}$ species is, on the other hand, hardly affected in the bulk. This is in contrast to the slow increase in the $\mathrm{S}-\mathrm{C}$ component in the surface region (Figure 3). From the results in Figures 3 and 4 , the crosslink formation process of the rubber compound is described as follows: The crosslink formation is a very fast process even at $374 \mathrm{~K}$ because the majority of the $\mathrm{S}-\mathrm{C}$ bond formation is already completed within the first $1 \mathrm{~h}$ (Figure 3d). In the bulk of the rubber compound, the crosslink formation reaches saturation within $1 \mathrm{~h}$ at $T=440 \mathrm{~K}$ (Figure 4e). The fast S-C bond formation in the first $1 \mathrm{~h}$ is due to the lower activation energy of sulfur vulcanization in the initial stages in comparison with those in the latter stages, as suggested by Wang et al. [9]. In addition to the fast $\mathrm{S}-\mathrm{C}$ bond formation, a slow bond formation also proceeds but only in the surface and near-surface region with the time constant longer than $170 \mathrm{~h}$. Since the apparent activation energy for this slow crosslink formation is found to be negative from the analysis of the Arrhenius plot, the reaction must compete with the $\mathrm{S}-\mathrm{C}$ bond scission, whose activation energy should be higher by $0.2 \mathrm{eV}$ than that of the $\mathrm{S}-\mathrm{C}$ bond formation.

The rubber compound examined in the present study has a very low accelerator/sulfur ratio (0.06), as described in the experimental section. Formulation is typical for the steel belt rubber in which the sulfur additives are used for both crosslink formation in the rubber compound and the formation of cupper sulfides as an adhesive agent between rubber and steel cords embedded in the steel belt [18]. To realize a strong rubber-steel adhesion, a sufficient amount of sulfur is required to be migrated from the rubber compound to the adhesion interface. The present study reveals that migration of the free sulfur in the rubber compound is fast enough not to be consumed by the crosslink formation. Thus, the rubber compound with a low accelerator/sulfur ratio is suitable for not only the steel belt rubber but also the rubber compounds that are used in rubber-metal composite materials.

\section{Conclusions}

Chemical states and kinetics of sulfur in the rubber compound have been investigated by HAXPES utilizing synchrotron radiation. Depth-resolved measurements were carried out by photoelectron emission-angle-dependent measurements. Three S 1s peaks at 2470, 2472, and $2479 \mathrm{eV}$ are identified and are associated with the $\mathrm{S}$ atoms bonded directly to the $\mathrm{C}$ atoms (the $\mathrm{S}-\mathrm{C}$ species), the $\mathrm{S}$ atoms bonded only to other $\mathrm{S}$ atoms (the $\mathrm{S}-\mathrm{S}$ species), and the $\mathrm{S}$ atoms in $\mathrm{SO}_{4}^{2-}$, respectively. The former two species show completely different response to the thermal treatment; the density of $\mathrm{S}-\mathrm{C}$ species is hardly changed in the bulk as deep as $34 \mathrm{~nm}$ or slightly increases in the surface and near-surface regions of the compound, whereas a significant loss of the S-S species is observed in both bulk and surface regions. 
The $\mathrm{S}-\mathrm{C}$ species are related to sulfur crosslink, while the $\mathrm{S}-\mathrm{S}$ species are polymeric sulfur including $\mathrm{S}_{8}$ additives. The Arrhenius plot analysis reveals that the $\mathrm{S}-\mathrm{C}$ bond scission should compete with the $\mathrm{S}-\mathrm{C}$ bond formation with a slightly higher activation energy by $0.2 \mathrm{eV}$ than that of the bond formation. The present study proves that HAXPES is capable to simultaneously investigate the chemical states of the composite elements (sulfur in the present case) and their kinetics in the rubber compound.

\section{Acknowledgements}

The HAXPES measurements at BL47XU of SPring- 8 were carried out under the approval of the Japan Synchrotron Radiation Research Institute (Proposal Nos. 2015A1663 and 2015B1578). The authors are grateful to Y. Kimura and K. Tobishima of Hirosaki University for their support in the HAXPES measurements.

\section{References}

[1] Akiba M., Hashim A. S.: Vulcanization and crosslinking in elastomers. Progress in Polymer Science, 22, 475521 (1997).

https://doi.org/10.1016/S0079-6700(96)00015-9

[2] Jeon G-S.: Adhesion between rubber compounds containing various adhesion promoters and brass-plated steel cords. Part I. Effect of sulfur loading in rubber compounds. Journal of Adhesion Science and Technology, 22, 1223-1253 (2008).

https://doi.org/10.1163/156856108X319926

[3] Chouch S-H., Chang D-H.: Kinetics of sulfur vulcanization of NR, BR, SBR, and their blends using a rheometer and DSC. Journal of Applied Polymer Science, 61, 449-454 (1996).

https://doi.org/10.1002/(SICI)10974628(19960718)61:3<449::AID-APP7>3.0.CO;2-I

[4] Milani G., Leroy E., Milani F., Deterre R.: Mechanistic modeling of reversion phenomenon in sulphur cured natural rubber vulcanization kinetics. Polymer Testing, 32, 1052-1063 (2013).

https://doi.org/10.1016/j.polymertesting.2013.06.002

[5] Halladay J. R., Warren P. A.: Rubber to metal bonding. in 'Handbook of rubber bonding' (ed.: Crowther B.) Rapra, Shawbury, 57-79 (2003).

[6] van Ooij W. J.: Mechanism and theories of rubber adhesion to steel tire cords - An overview. Rubber Chemistry and Technology, 57, 421-456 (1984). https://doi.org/10.5254/1.3536016

[7] Choi S-S.: Influence of thermal aging on change of crosslink density and deformation of natural rubber vulcanizates. Bulletin of the Korean Chemical Society, 21, 628-634 (2000).
[8] Ding R., Leonov A. I.: A kinetic model for sulfur accelerated vulcanization of a natural rubber compound. Journal of Applied Polymer Science, 61, 455-463 (1996). https://doi.org/10.1002/(SICI)10974628(19960718)61:3<455::AID-APP8>3.0.CO;2-H

[9] Wang P-Y., Qian H-L., Yu H-P., Chen J.: Study on kinetic of natural rubber vulcanization by using vulcameter. Journal of Applied Polymer Science, 88, 680-684 (2003). https://doi.org/10.1002/app.11632

[10] Coran A. Y.: Vulcanization. Part V. The formation of crosslinks in the system: Natural rubber-sulfur-MBTzinc ion. Rubber Chemistry and Technology, 37, 679688 (1964).

https://doi.org/10.5254/1.3540360

[11] Coran A. Y.: Vulcanization. Part VI. A model and treatment for scorch delay kinetics. Rubber Chemistry and Technology, 37, 689-697 (1964).

https://doi.org/10.5254/1.3540362

[12] Coran A. Y.: Vulcanization. Part VII. Kinetics of sulfur vulcanization of natural rubber in presence of delayedaction accelerators. Rubber Chemistry and Technology, 38, 12-14 (1965). https://doi.org/10.5254/1.3535628

[13] Woicik J. C.: Hard X-ray photoelectron spectroscopy (HAXPES).Springer, Basel (2016).

[14] Ikenaga E., Kobata M., Matsuda H., Sugiyama T., Daimon H., Kobayashi K.: Development of high lateral and wide angle resolved hard X-ray photoemission spectroscopy at BL47XU in SPring-8. Journal of Electron Spectroscopy and Related Phenomena, 190, 180-187 (2013). https://doi.org/10.1016/j.elspec.2013.04.004

[15] Ghorai S., Jalan A. K., Roy M., Das A., De D.: Tuning of accelerator and curing system in devulcanized green natural rubber compounds. Polymer Testing, 69, 133145 (2018). https://doi.org/10.1016/j.polymertesting.2018.05.015

[16] Ozawa K., Kakubo T., Amino N., Mase K., Ikenaga E., Nakamura T.: Angle-resolved HAXPES investigation on the chemical origin of adhesion between natural rubber and brass. Langmuir, 33, 9582-9589 (2017). https://doi.org/10.1021/acs.langmuir.7b01842

[17] Ozawa K., Kakubo T., Shimizu K., Amino N., Mase K., Ikenaga E., Nakamura T., Kinoshita T., Oji H.: In situ chemical state analysis of buried polymer/metal adhesive interface by hard X-ray photoelectron spectroscopy. Applied Surface Science, 320, 117-182 (2014). https://doi.org/10.1016/j.apsusc.2014.09.012

[18] Ozawa K., Kakubo T., Shimizu K., Amino N., Mase K., Komatsu T.: High-resolution photoelectron spectroscopy analysis of sulfidation of brass at the rubber/brass interface. Applied Surface Science, 264, 297-304 (2013). https://doi.org/10.1016/j.apsusc.2012.10.015 
[19] Tokyda S., Okabayashi J., Oshima M., Liu G. L., Liu Z., Ikeda K., Usuda K.: Chemical-state-resolved in-depth profiles of gate-stack structures on Si studied by angular-dependent photoemission spectroscopy. Surface and Interface Analysis, 40, 1619-1622 (2008).

https://doi.org/10.1002/sia.2997

[20] Jablonski A., Powell C. J.: Practical expressions for the mean escape depth, the information depth, and the effective attenuation length in Auger-electron spectroscopy and X-ray photoelectron spectroscopy. Journal of Vacuum Science and Technology A, 27, 253-261 (2009). https://doi.org/10.1116/1.3071947
[21] Seah M. P.: An accurate and simple universal curve for the energy dependent electron inelastic mean free path. Surface and Interface Analysis, 44, 497-503 (2012). https://doi.org/10.1002/sia.4816 